\title{
PEDESTRIAN BRIDGES AS ELEMENTS OF THE NEW URBAN IDENTITY OF CITIES
}

Scientific paper

(Received: 8 December 2020; accepted: 22 February 2021)

\section{Željka Jurković}

Josip Juraj Strossmayer University of Osijek, Faculty of Civil Engineering Osijek, assistant professor Corresponding author: zjurkovic@gfos.hr

\section{Željko Koški}

Josip Juraj Strossmayer University of Osijek, Faculty of Civil Engineering Osijek, associate professor

\section{Danijela Lovoković}

Josip Juraj Strossmayer University of Osijek, Faculty of Civil Engineering Osijek, lecturer

\begin{abstract}
By the start of the $21^{\text {st }}$ century, the majority of the world's population was living in cities. Therefore, a top priority has been solving the problem of connecting parts of the city divided by traffic infrastructure in the shortest possible manner by using pedestrian paths. The aim of this study was to analyze, systematize, and typologically define the specific types of structures that make this possible, specifically pedestrian bridges located above roads and railway corridors. The primary and secondary requirements that must be met when designing a pedestrian bridge were identified, and an analysis and comparison of examples of constructed pedestrian bridges in Croatia and the world are herein presented. The results of this study enable the conclusion that, in recent times, in the age of the spectacle society and spectacle architecture, pedestrian bridges are simultaneously deemed architecture, engineering, and infrastructure projects. They are becoming new elements in a city's image and contribute to the creation of a new urban identity. The original design of pedestrian bridges fosters the use of different construction systems and materials in accordance with technical and technological advancements in construction.
\end{abstract}

Keywords: Pedestrian bridges; typology; architectural design; urban identity. 


\section{INTRODUCTION}

Global urbanization processes at the end of the $20^{\text {th }}$ century and start of the $21^{\text {st }}$ century have resulted in more than half of the world's population living in cities. Solving the problem of pedestrian paths within cities in the shortest possible manner is one of the most important tasks for improving the quality of life of the population, particularly in large cities. Because of their specific requirements, only pedestrian bridges with roofs as protection from rainfall that are located over roads and railway traffic corridors were analyzed in this study. Shortening of pedestrian paths requires adding levels for crossing railway and road barriers to enable all types of traffic to flow within a city in a smooth and safe manner [1]. While they were once solely engineering projects, by the end of the $20^{\text {th }}$ century and start of the $21^{\text {st }}$ century, pedestrian bridges have become unique architectural and structural projects (Fig. 1). In addition to helping pedestrians cross traffic barriers, pedestrian bridges contribute to the physical continuity of the city's built-up structure above a railway corridor or road. In the design of pedestrian bridges, the use of different construction systems and materials was examined: reinforced concrete, steel, glass, wood, polycarbonate sheets, membranes, and synthetic and polymeric materials. Uniquely designed pedestrian bridges are becoming increasingly distinguished elements within a city's landscape, representing an important factor in creating the city's image and urban identity [2].

Successful construction of a pedestrian bridge improves the urban spatial context by considering the surrounding architecture, surrounding views, climatic conditions, and actual needs of pedestrians and cyclists. Specifically, the shortest, almost vectorial crossing of a traffic barrier is considered. The specific purpose for public use of a pedestrian bridge is to primarily satisfy the everyday functional needs of pedestrians and cyclists (i.e., nonmotorized traffic). The social component of gathering or spending time in this type of public space is secondary. Moreover, pedestrian bridges represent a crossing that is not simply the physical crossing of a barrier; rather, the crossing is an experience of movement, of spatial and sensory stimuli, primarily visual stimuli [3].

Considering their function, pedestrian bridges are monofunctional, single-space structures that cannot be organized in a flexible manner. This study focused on analyzing pedestrian bridges in Croatia (Fig. 1(a) and 1(c)) and compared them to constructed pedestrian bridges in other locations around the world (Fig. 1(b) and 1(d)).

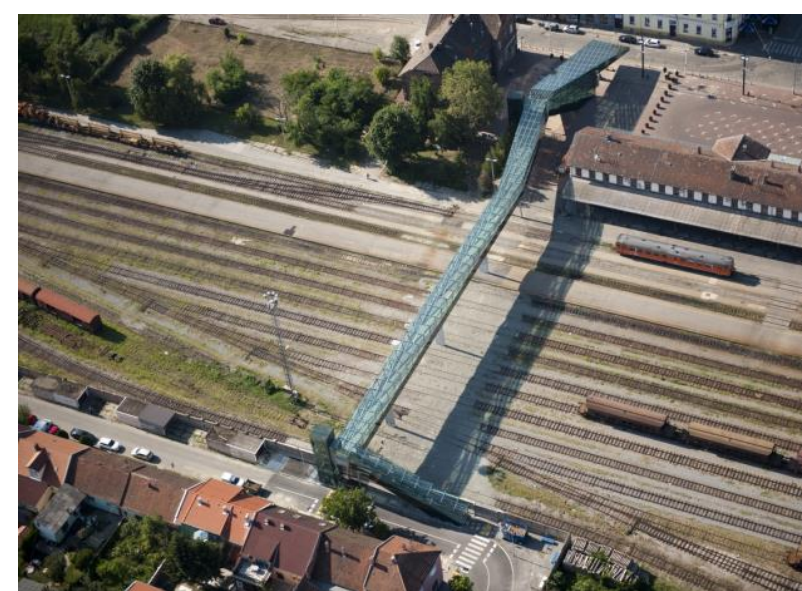

(a)

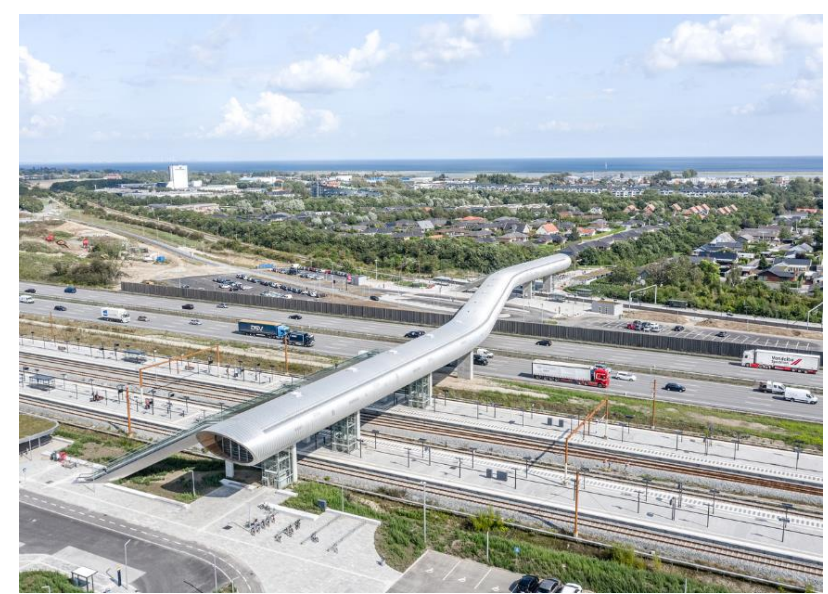

(b)

Jurković, Ž, Koški, Ž, Lovoković, D 


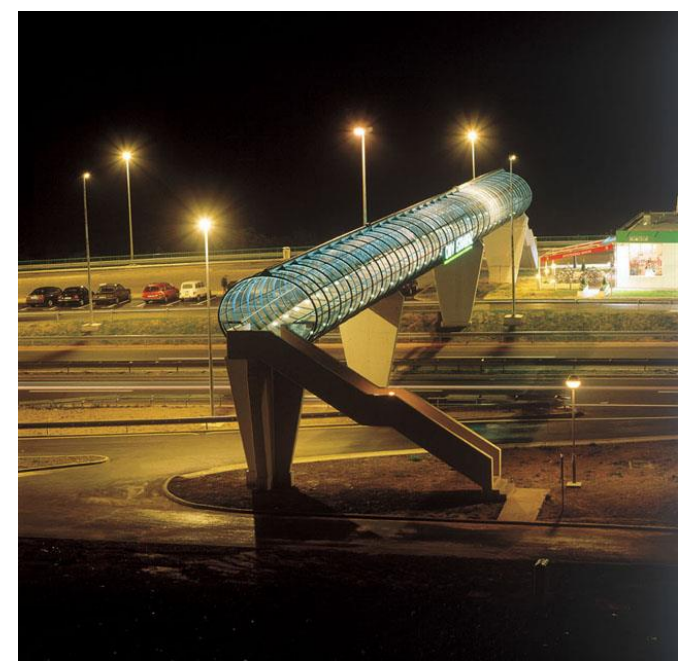

(c)

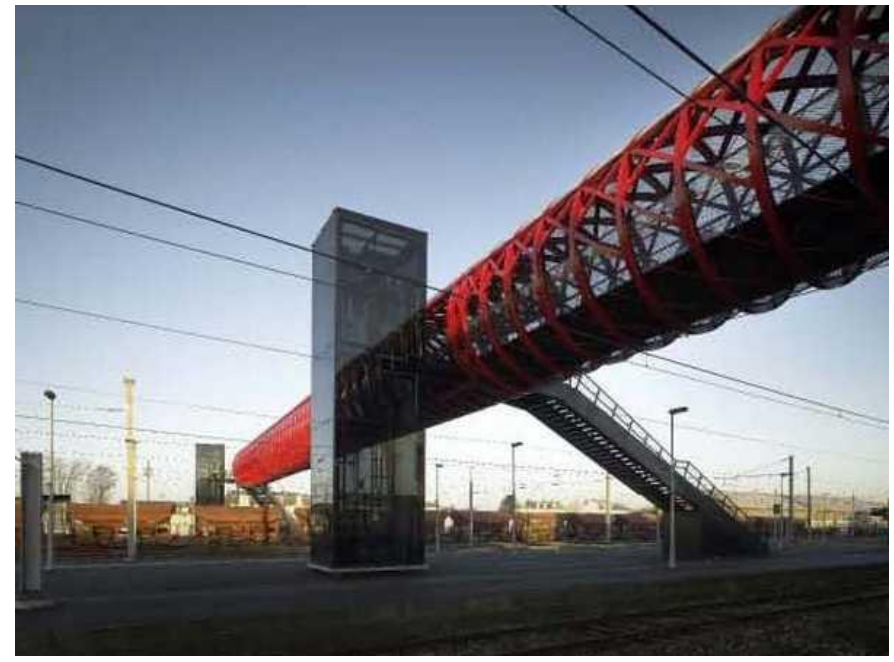

(d)

Figure 1 Constructed pedestrian bridges in Croatia and elsewhere in the world: (a) Pedestrian bridge at the railway station, Osijek, Croatia, architects: Branimir Kljajić and Goran Jagić, 2009; (b) Pedestrian bridge at the Køge North Station, Køge, Denmark, architects: Cobe, DISSING+WEITLING Architecture, 2019 [4]; (c) Pedestrian bridge "Gate of the Adriatic" over a road, Rijeka, Croatia, architects: Randić and Turato, 1998 [5]; (d) Pedestrian bridge at the railway station, La Roche-Sur-Yon, France, architect: Bernard Tschumi, 2010 [6]

\section{RESEARCH OBJECTIVE AND METHODS}

The purpose of this research was to examine the requirements for designing a pedestrian bridge and to systematically analyze the functional, design, and structural characteristics of pedestrian bridges. Moreover, the types of pedestrian bridges used were to be typologically determined based on the basic forms of their floor plans, the materials used for the load-bearing structure, and the shape of the cross-section. The research methods of this study included an initial analysis of professional and scientific literature and an overview of the research conducted in this area to date. The collected data were processed using the inductive approach and analysis and comparison. For pedestrian bridges in Croatia, the method of in-situ observation was used and photographs were obtained. Using the generalization method, the research results were synthesized into a conclusion.

\section{REQUIREMENTS IN DESIGNING PEDESTRIAN BRIDGES}

The elements of a functional organization are identical in most pedestrian bridges. The basic structure of a pedestrian bridge consists of two elements: the entry/exit (ascent/descent) element as the vertical component, and the body of the pedestrian bridge as the horizontal component. Entry/exit points may be integrated in the body of the pedestrian bridge or located separately as individual elements. It can be concluded that the primary function of a pedestrian bridge is connectivity: at a certain height, non-motorized traffic consisting of pedestrians and cyclists crosses the road or railway barrier. Pedestrian bridges are typically constructed at attractive locations in the central part of the city or in heavy traffic areas, often next to railway stations and factories, i.e., at locations visited by a large number of people. They are noticeable in the space, visually dominant in their surroundings, and they consequently become part of the city's landscape (Fig. 1). In the social age and era of spectacle architecture, the unique design of a pedestrian bridge emerges as the city's symbol, an element of its visual identity and image [2]. For that reason, many scholars believe that requests for the original and attractive design of pedestrian bridges, integrated into the structural concept, are justified. They believe that the design is one of the basic requirements in planning pedestrian bridges [1], [2], [7]. Pedestrian bridges do not have to bear a great moveable load, which is why they are appropriate for researching new structural systems, forming complex geometric shapes, and employing new materials. The research processes of structure and form currently exist as computer-aided processes. Without these processes, it is impossible to create, 
present, or construct complex spatial structures [8]. It is precisely the variations of new three-dimensional structural and planning concepts that contribute the most to the uniqueness of pedestrian bridges, creating a specific, almost crafted, or manufactured-like architecture (Fig. 1, Fig. 3, Fig. 4, Fig. 5).

More than other types of buildings, pedestrian bridges require an integrational, multidisciplinary approach for their design, which includes interactive cooperation, primarily between the architect and the structural engineer [8] as well as the mechanical and electrical engineer. The diagram of the pedestrian bridge design process is identical to the diagram of the bridge design process (Fig. 2). The bridge design flow chart is represented in Fig. 2. It shows that, after the function of the bridge is determined based on traffic planning (in this case, a pedestrian bridge), the process continues with shaping the form and selection of materials of the pedestrian bridge [7].

\begin{tabular}{lll}
\hline PURPOSE & $\rightarrow$ & FUNCTION \\
& & $\downarrow$ \\
MATERIAL & $\rightarrow$ & $\frac{1}{\text { FORM }}$ \\
STYLE & $\rightarrow$ & $\frac{\text { BRIDGE }}{\text { (PEDESTRIAN BRIDGE) }}$
\end{tabular}

\section{Figure 2 Diagram of the bridge (pedestrian bridge) design process [7]}

The requirements that must be met when designing a pedestrian bridge can be grouped into two categories: primary and secondary. The primary category consists of the basic requirements to be fulfilled:

- Logical and functional urban location to create the shortest paths for pedestrians and cyclists;

- Unique and original planning with an appropriate construction concept;

- Durability and safety of materials used;

- Acceptable construction and maintenance cost;

- Ensured safety of crossing;

- Consideration of climatic conditions;

- Human scale;

- Accessibility for persons with reduced mobility.

The secondary requirements include those that build on the basic requirements:

- Reduction of airborne noise and acoustic properties;

- Attractive views from the pedestrian bridge of the surrounding area and from the surrounding area to the pedestrian bridge;

- Night views;

- Experience and memory of crossing;

- Potential for social interaction.

Meeting of the above requirements in the design is a prerequisite for creating new spatial, traffic, and social values [9]. Although the construction of a pedestrian bridge is mainly used to solve a single traffic and spatial conflict points, the construction of pedestrian bridges may also promote changes in the surrounding city structure, while stimulating the process of revitalization or transformation of surrounding derelict roads or railway spaces [10].

\section{TYPES OF PEDESTRIAN BRIDGES}

There are many different planning and structural concepts for pedestrian bridges [1]. Considering their various forms, innovative construction concepts, and materials used, pedestrian bridges can be divided into certain aspects, such as formal (artistic) and structural (technical) aspects. The length of the pedestrian bridge depends on the width of the road/railroad, while the width of the pedestrian bridge depends on the type and intensity of traffic on the pedestrian bridge. Pedestrian traffic on these bridges may be related to the activities of arrival/departure from work (rush hour), shopping, attending sports or music events, etc. The dimensions of the pedestrian bridge are determined accordingly [9]. Certain countries (e.g., Japan, Germany, Australia, Great Britain, and South Korea) have regulations prescribing the width of pedestrian and cyclist bridges. In Croatia, the minimum width of a pedestrian bridge is regulated by the Ordinance on Ensuring Access to Structures for Disabled Persons and Persons with Reduced Mobility (Official Gazette 78/13), Article 39 , of which stipulates that the minimum width of the walkway within a pedestrian bridge is $150 \mathrm{~cm}$. 


\subsection{Classification of pedestrian bridges according to their basic form}

Based on the basic form of their floor plans, pedestrian bridges may be categorized as linear or circular pedestrian bridges, and pedestrian bridges that combine different types of floor plans [9]. All pedestrian bridge forms share the following characteristics: they are "hollow," single-space architectural structures raised above the ground. The most common types of pedestrian bridges are linear pedestrian bridges, which use the shortest, practically vectorial path to connect two points, with a predominant direction and clearly positioned and explicit entry/exit points. The construction of linear pedestrian bridges is typically used to bridge large gaps (Fig. 3(a) and 3(b)). Linear pedestrian bridges are relatively narrow, typically $3-4 \mathrm{~m}$, and they are used for linear two-way movement of pedestrians and cyclists.

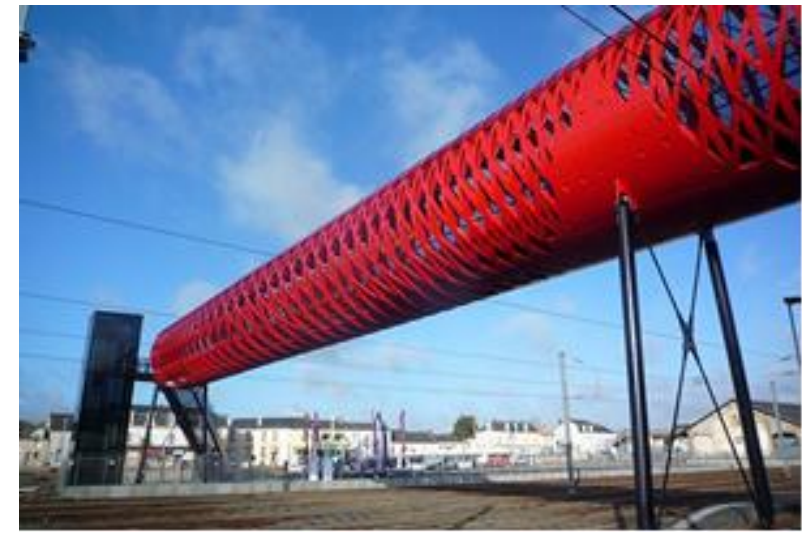

(a)

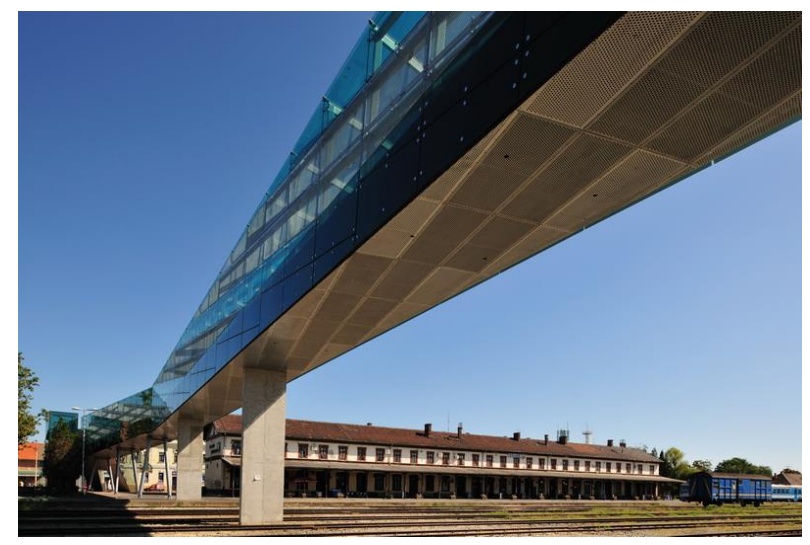

(b)

Figure 3 Linear pedestrian bridges: (a) Pedestrian bridge at the railway station, La Roche-Sur-Yon, France, architect: Bernard Tschumi, 2010 [11]; (b) Pedestrian bridge at the railway station, Osijek, Croatia, architects: Branimir Kljajić and Goran Jagić, 2009

Circular pedestrian bridges are constructed at intersections to ensure continuous movement of pedestrians and cyclists by connecting several possible entry/exit points. Such pedestrian bridges connect several city blocks divided by intense traffic (Fig. 4(a) and 4(b)). Movement is circular or semi-circular, with pronounced dynamic movements and spatial experiences for pedestrians. All entry/exit points are usually equally important because there is no predominant direction.

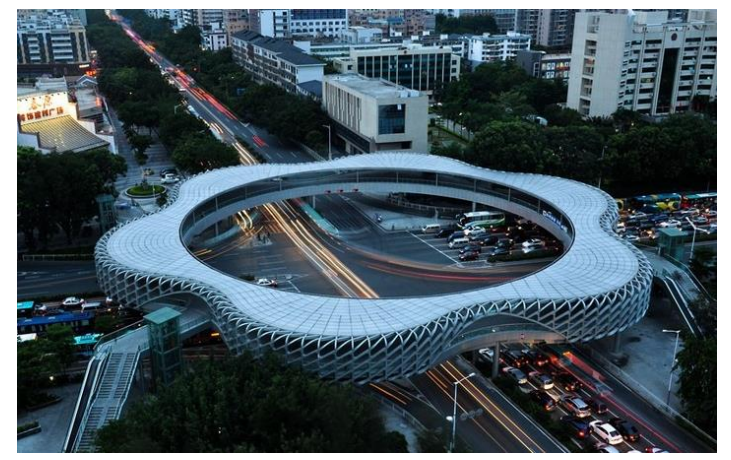

(a)

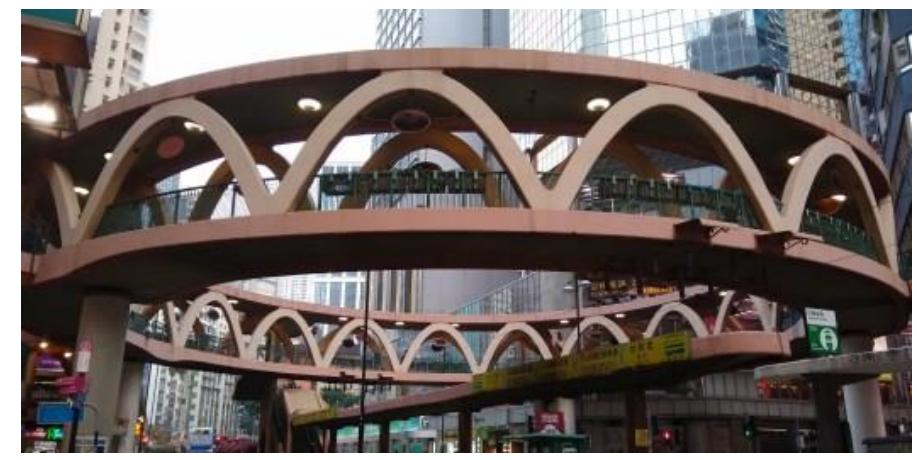

(b)

Figure 4 Circular pedestrian bridges: (a) Pedestrian bridge over an intersection, Shenzhen, China, 2012 [12]; (b) Pedestrian bridge over an intersection, Hong Kong, China [13]

Pedestrian bridges may combine different forms of floor plans and different directions of movement, while having more than two entry/exit points (Fig. $5(\mathrm{a})$ and $5(\mathrm{~b})$ ). 


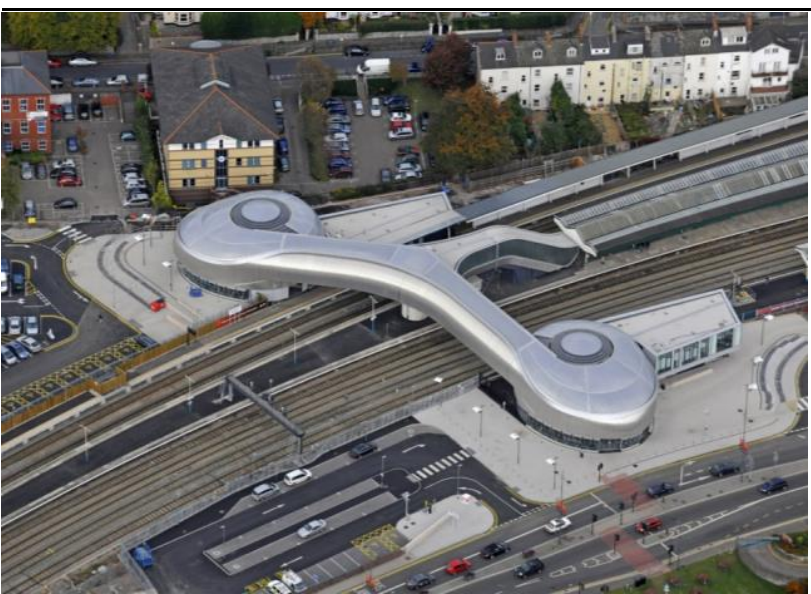

(a)

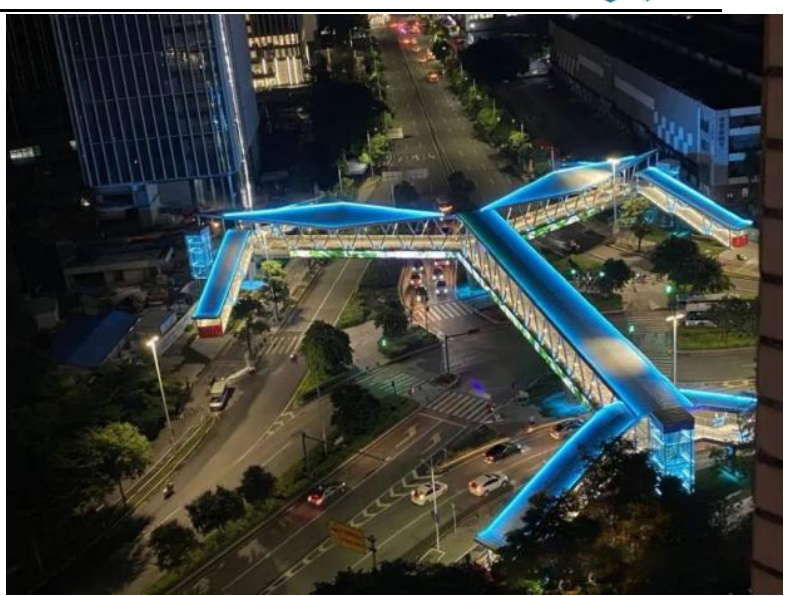

(b)

Figure 5 Combined-form pedestrian bridges: (a) Pedestrian bridge at the railway station, Newport, Great Britain, architects: Grimshaw, 2010 [14]; (b) Pedestrian bridge over an intersection, Shenzhen, China [15]

\subsection{Classification according to basic construction material}

Metal load-bearing structures are the most common structures that are used for pedestrian bridges, regardless of whether the metal employed is steel, stainless steel, or aluminum. Metal use enables a variety of construction and planning concepts, can bridge wide gaps, and is easily combined with other materials, while its management and replacement of installations are simple. Steel has a good mechanical resistance to weight ratio; thus, the structure confers an aesthetic of elegance, lightness, and transparency [7]. In regard to the increasingly proliferating environmental protection requirements, steel structures do not cause environmental pollution during their construction and lifetime, and their assembly is quick and simple (Fig. 1(b)). Owing to their locations in open spaces, pedestrian bridge structures are intensely exposed to weather conditions and the effects of motorized traffic (vehicle emissions, vibrations). On account of the physical and technical requirements to be met, use of wood for load-bearing structures of pedestrian bridges is in demand because it is an organic material. However, for long periods of use, a series of protective measures is necessary, which makes the construction more expensive and requires continuous maintenance in the long term. In outdoor conditions, wood is exposed to chemical and physical changes that have a negative effect on its aesthetics, durability, and stability. For that reason, pedestrian bridges constructed using only wood are rare. In pedestrian bridge architecture, the combination of wood and steel is common, where steel is used for the load-bearing structure and wood is used for the outer layer of the pedestrian bridge for the decorative elements, the lining, and the walkway (Fig. 6(a) and 6(b), Fig. 7, Fig. 8(b)). 


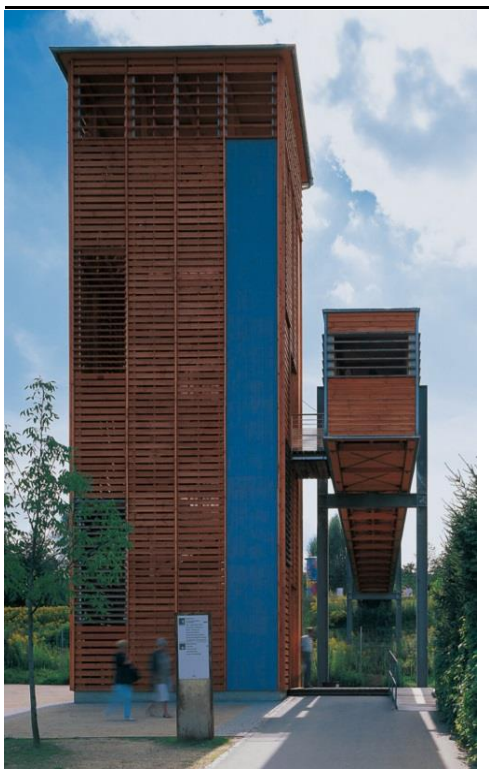

(a)

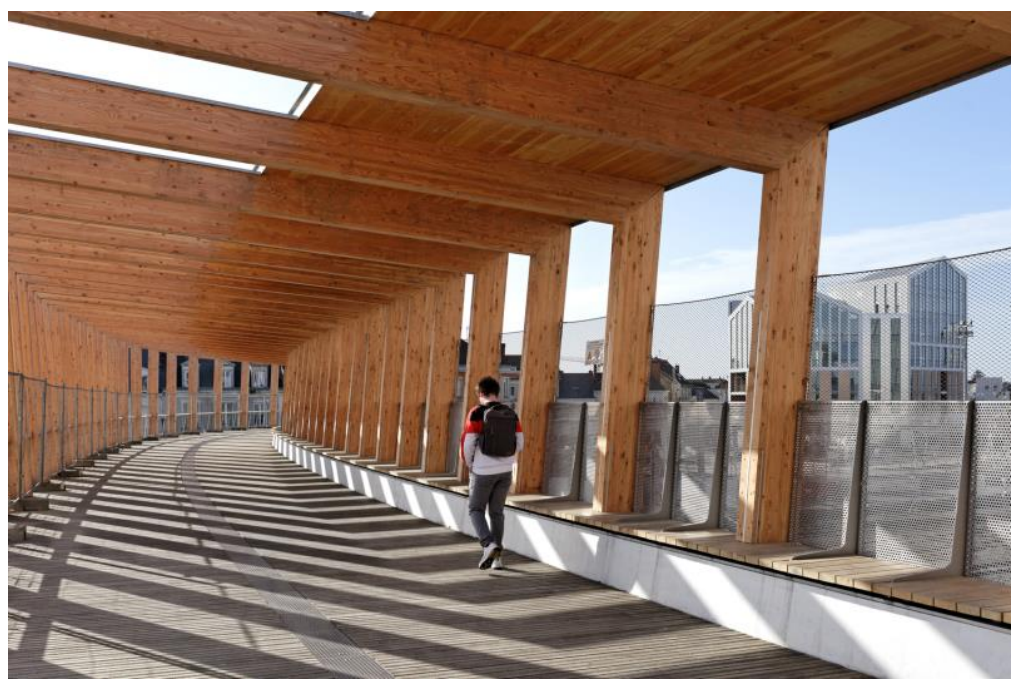

(b)

Figure 6 Use of wooden elements in pedestrian bridges: (a) Pedestrian bridge over a railway corridor, Singen, Germany, architect: Jürgen Usleber, 2001 [16]; (b) Pedestrian bridge over a railway corridor, Angers, France, architects: Dietmar Feichtinger Architectes, 2020 [17]

Pedestrian bridges built entirely out of reinforced concrete are relatively rare. The basic material (reinforced concrete) cannot bridge larger gaps using the flat slab system without additional support within the required length of the pedestrian bridge. Accordingly, placing additional support may incur functional and spatial limitations on the railroad or road traffic being bridged. On the other hand, use of reinforced concrete has multiple advantages: it is a durable material of great mechanical strength, it may be prefabricated or semi-prefabricated, it is resistant to biological and chemical effects, and its construction and maintenance costs are lower than those of other materials, such as wood or steel (Fig. 7, Fig. 13(b)).

Numerous constructed pedestrian bridges combine different load-bearing and finishing materials (reinforced concrete, steel, wood, load-bearing glass, glass, membranes, metal mesh, polycarbonate sheets), while the use of carbon fibers and different composite and polymeric materials is being studied [18], [19]. Depending on the required length and width of the pedestrian bridge and the gap to be bridged, the construction concepts applied to pedestrian bridges may differ (beam, frame, arch, lattice, suspension structure, spatial structure). 


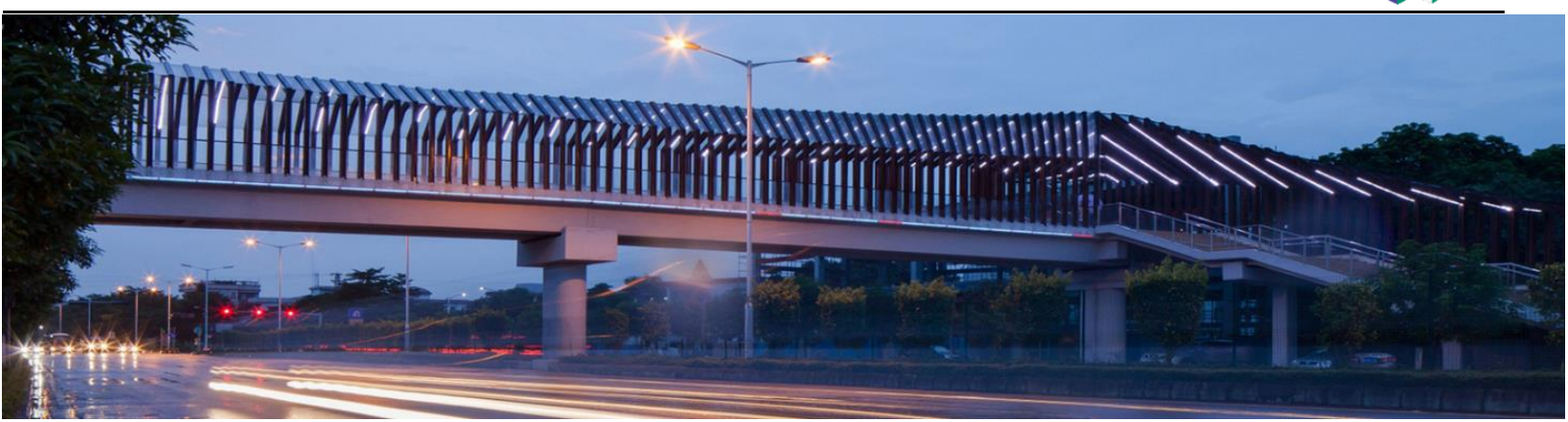

Figure 7 Pedestrian bridge over a road, Foshan, China, architects: ADARC Associates, 2015 [20]

\subsection{Classification of pedestrian bridges according to cross-section shape}

The specificity of the pedestrian bridge function does not involve time spent in the given area but rather the movement from the ascent point to the descent point. The interior of the pedestrian bridge is typically empty, with no additional spaces or rooms. From the perspective of the pedestrian passing through it, it is visually experienced primarily through movement. For that reason, the uniqueness of architecture of a pedestrian bridge is greatly reflected in the shape of its cross-section. Based on this shape, pedestrian bridges may have a rectangular or polygonal cross-section (Fig. 8(a) and (b)), a circular or elliptical cross-section (Fig. 9), and a variable cross-section (Fig. 10(a) and (b)).

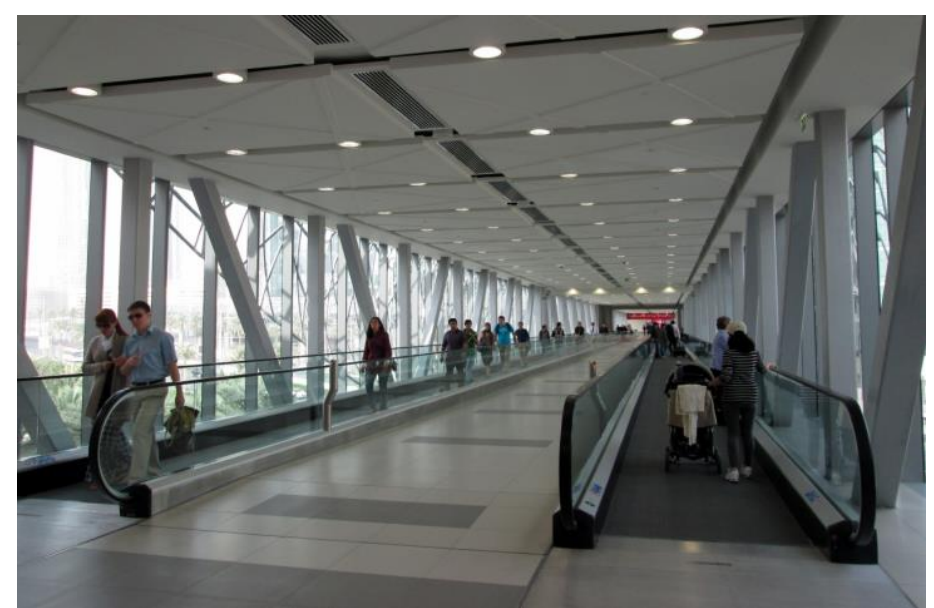

(a)

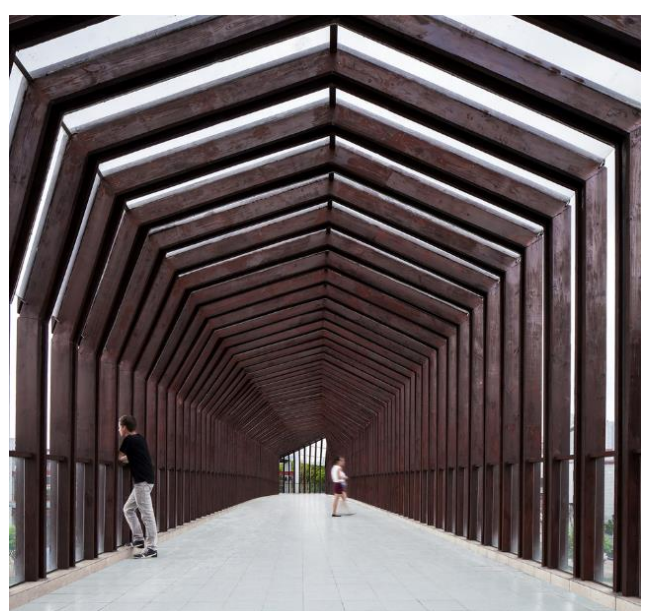

(b)

Figure 8 Rectangular or polygonal cross-section: (a) Pedestrian bridge over a road, Dubai, UAE, 2012 [21]; (b) Pedestrian bridge over a road, Foshan, China, architects: ADARC Associates, 2015 [22] 


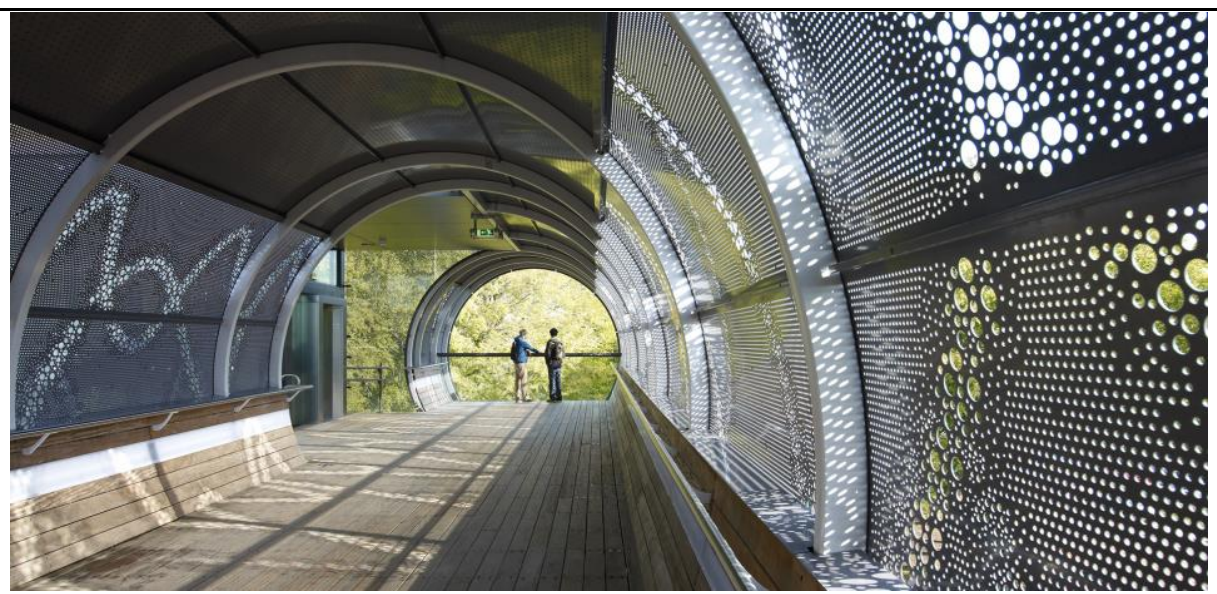

Figure 9 Circular or elliptical cross-section: Pedestrian bridge at the railway station, Hilversum, the Netherlands, architects: MVSA-architects, 2011 [23]

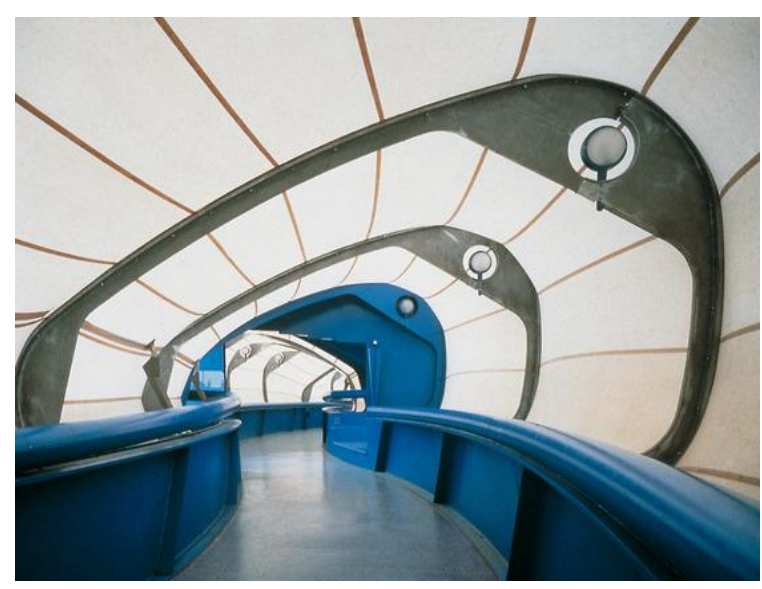

(a)

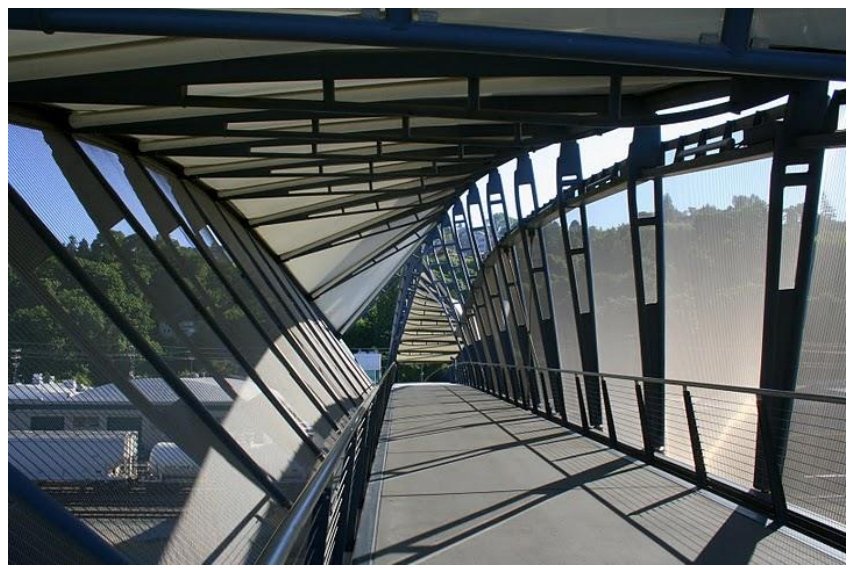

(b)

Figure 10 Variable cross-section: (a) Pedestrian bridge, London, Great Britain, architects: Birds, Portchmouth, Russum Architects, 2001 [24]; (b) Helix pedestrian bridge over a railway corridor, Seattle, USA, architects: Johnson Architecture, 2004 [25]

The sides and the roof may be more or less transparent and lined with different materials (glass, metal mesh, wood, membrane film, etc.). The sides enable natural ventilation of the pedestrian bridge's interior, mainly by using lattices or openings. An exception is pedestrian bridges in difficult climates, which often use air-conditioning. For example, by constructing pedestrian bridges that are an integral part of the metro network, Dubai aims to reduce road traffic and increase pedestrian traffic, while simultaneously maintaining the climate, safety, and convenience for the pedestrians. This is why larger pedestrian bridges are air-conditioned and additionally equipped with moving walkways (Fig. 8(a)).

\section{ENTRY AND EXIT POINTS}

The specific function of a pedestrian bridge requires at least two entry/exit points owing to the functional requirements of vertical traffic. In the case of natural denivelation of the landscape (Fig. 6 (a), Fig. 11 (a)), entry and exit points can be at the level of the terrain, or both entry and exit points can be elevated (Fig. 1 (a), (b), (c) and (d)). As a rule, pedestrian bridges have in the last two decades been equipped with lifts in addition to staircases. The crossing begins and ends at the entry/exit points, not only in terms of function, but also in the psychological sense. Entry/exit 
points may intentionally be constructed using different materials and forms than the characteristic cross-section of the body of the pedestrian bridge. However, they may also function as a continuation of the cross-section or form of the pedestrian bridge (Fig. 11(a) and (b)).

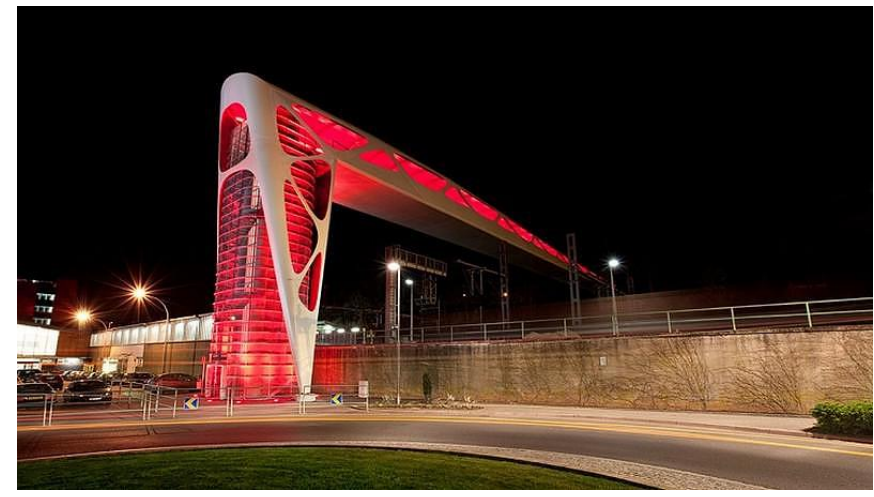

(a)

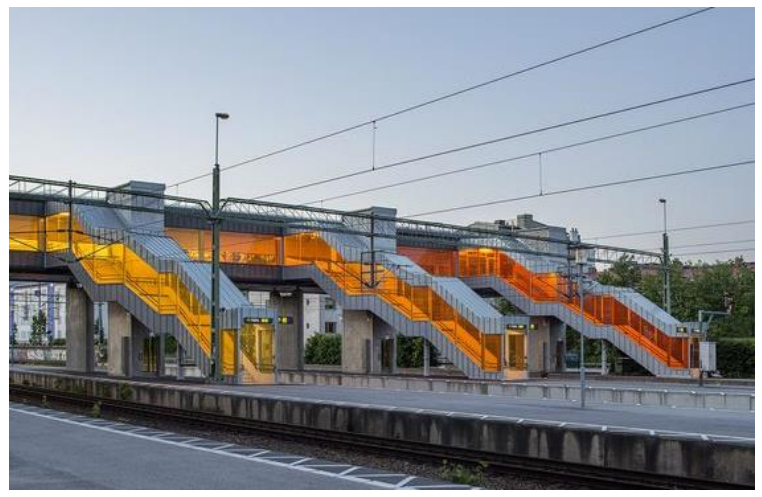

(b)

Figure 11 Entry/exit points of pedestrian bridges: (a) Pedestrian bridge at the railway station, Esch, Luxemburg, architects: Metamorf Architects and T6-Ney and Partners, 2009 [26]; (b) Pedestrian bridge at the railway station, Lund, Sweden, architect: Metro Arkitekter, 2014 [27]

\section{PEDESTRIAN BRIDGES IN CROATIA}

Pedestrian crossings are pedestrian bridges without a roof. Earlier pedestrian crossings bridging railway corridors or roads in Croatia were mostly built as standard latticed steel structures whose sole purpose was for pedestrians to cross from one side of a road to the other. The crossings were designed without original effort and with no ambition to create an architectural landmark in the city's image (Fig. 12, Fig. 13(a), Fig. 14(a)). They were primarily built near railway stations (Zagreb, Osijek, Slavonski Brod) or in the immediate vicinity of factories employing a large number of workers (TOZ factory, Zagreb; Đuro Đaković factory, Slavonski Brod; Sugar factory, Osijek), thereby providing a safe crossing over the railroad for the workers. These were pedestrian crossings with a latticed steel structure and side rails, without a roof and with no protection against the weather. This type of structure cannot be typologically defined as a pedestrian bridge; rather, it is deemed a pedestrian crossing.

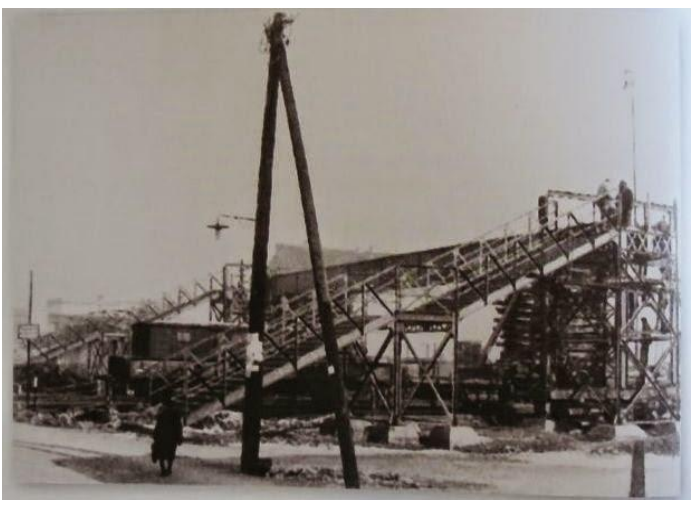

(a)

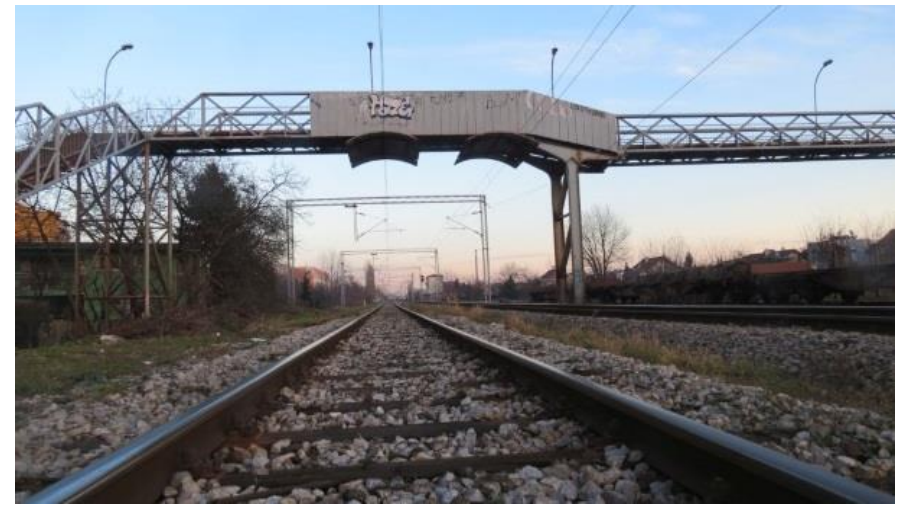

(b)

Figure 12 Pedestrian crossings over railway corridors: (a) Crossing over a railway corridor, Rural Road, Zagreb, Croatia (dismantled) [28]; (b) Crossing over a railway corridor, Kustošija city district, Zagreb, Croatia [29]

In Zagreb, such older pedestrian crossings could be found at the main railway station, at Rural Road (Fig. 12(a)), and in the city districts of Borongaj and Svetice. The crossing in Kustošija, connecting llica and Poljička Ulica 
(i.e., the TOZ factory), still exists today (Fig. 12(b)). All other crossings have been dismantled: the one in Borongaj was dismantled in 1969 as part of the preparations for electrification of the railroad, and the one near the main railway station was dismantled in 1979 when a pedestrian underpass was opened to the public.

In Osijek, the old and derelict crossings near the railway station in Gornji grad (Fig. 13(a)) and near the Sugar factory in the Donji grad city district have been dismantled (Fig. 14(a)). Both crossings were torn down in 2007, and new pedestrian bridges with a roof and sides were constructed for pedestrians and cyclists at those locations.

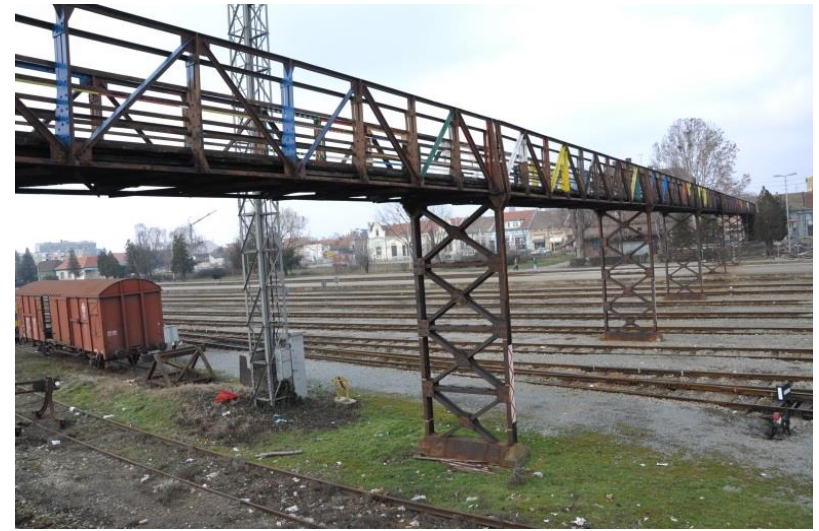

(a)

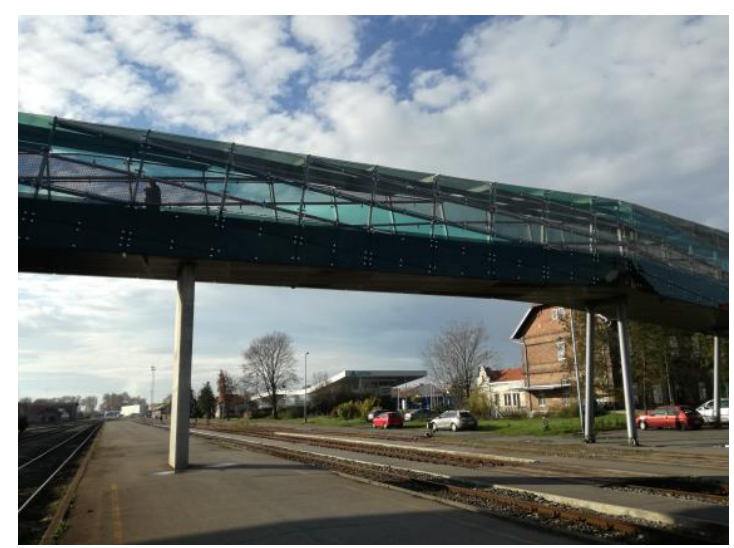

(b)

Figure 13 Side-to-side comparison of the dismantled crossing and the new pedestrian bridge: (a) Crossing at the railway station, Osijek, Croatia (dismantled); (b) Pedestrian bridge at the railway station, Osijek, Croatia, architects: Branimir Kljajić and Goran Jagić, 2009

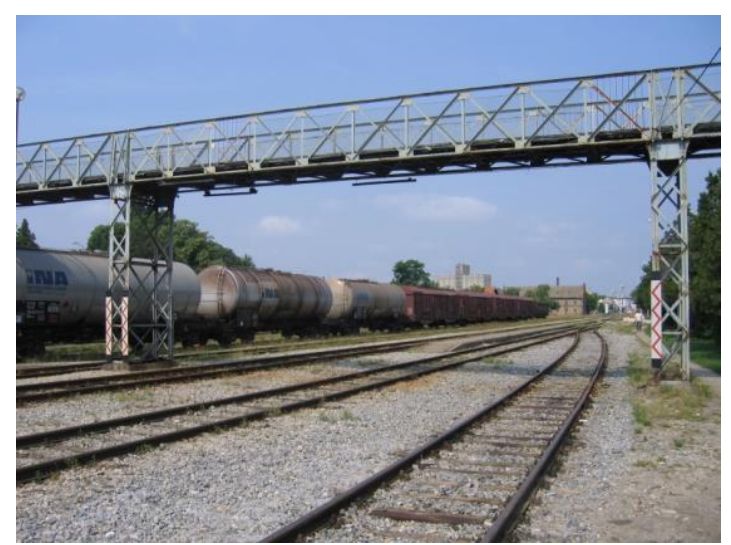

(a)

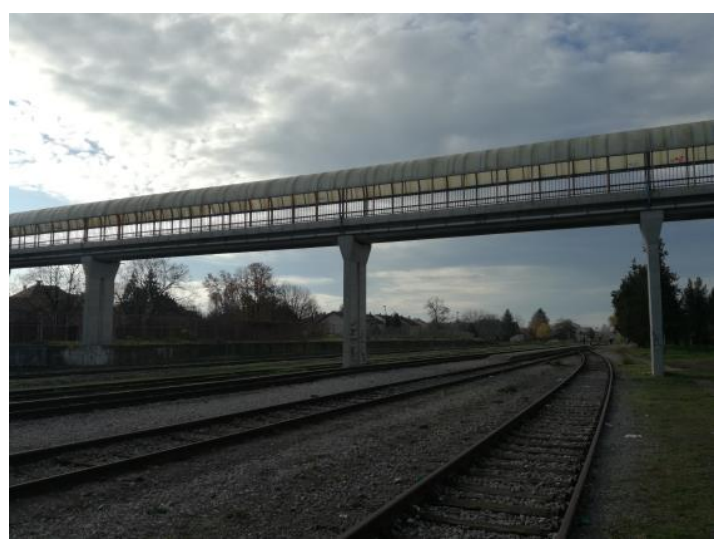

(b)

Figure 14 Side-to-side comparison of the dismantled crossing and the new pedestrian bridge: (a) Crossing over a railway corridor at the Sugar factory, Osijek, Croatia (dismantled); (b) Pedestrian bridge over a railway corridor at the Sugar factory, Osijek, Croatia, architect: Assoc. Prof. Željko Koški, PhD, other authors: Prof. Zvonimir Marić, PhD, Prof. Damir Markulak, PhD, and Prof. Damir Varevac, PhD, 2005

The first exception to the practice of building standard steel crossings in Croatia was the pedestrian bridge at the railway station in the city of Slavonski Brod, which connected the square in front of the railway station with the Đuro Đaković factory. The pedestrian bridge was 280 meters long. It was constructed and opened for pedestrian traffic in 1988 [30]. A pioneering example of architecture and engineering, it was not simply a prefabricated standard steel structure; based on the descriptions of citizens at the time when it was constructed, it had a "futuristic" look (Image 15(a)). The pedestrian bridge was constructed with a steel load-bearing structure and an elliptical crosssection, while the surface area was constructed using bent polycarbonate sheets (Fig. 15(b)). Today, the pedestrian 
bridge is poorly maintained, with cracked or missing elements of polycarbonate sheets, a worn concrete walkway, and poorly maintained steel structure elements.

The example of the pedestrian bridge in Slavonski Brod shows that uniquely structured buildings that are exposed to intense pedestrian traffic, weather conditions, vibrations, and other effects on the structure and surface area must be heavily maintained to enable the retention of their structural uniqueness, envisioned manner of use, stability, and appearance of the materials used.

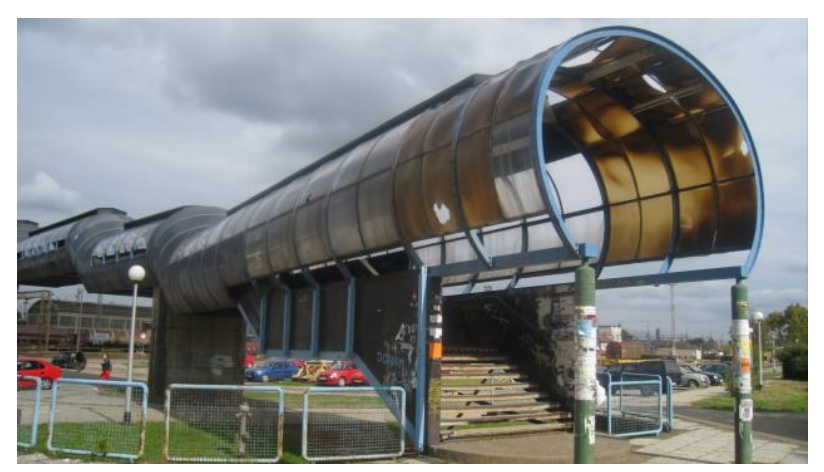

(a)

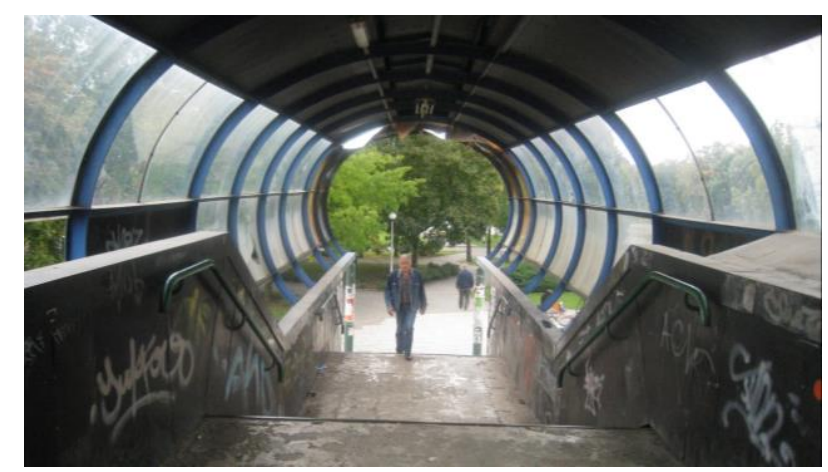

(b)

Figure 15 Pedestrian bridge at the railway station, Slavonski Brod, Croatia, authors: Duško Medaković (conceptual design and architecture), Dušan Bošnjak (construction), 1988: (a) Entry point of the pedestrian bridge on the south side; (b) Elliptical cross-section

The next step forward in the construction of pedestrian bridges in Croatia occurred in 1998, with the construction of the pedestrian bridge Vrata Jadrana above the Adriatic highway near Rijeka (Fig. 1(c)). The pedestrian bridge is part of a gas station complex in the location where travellers/tourists receive their first views of the Adriatic Sea. This context of the project required a concept of the pedestrian bridge as a well-rounded product, i.e., an object that cannot have any parts that would have to be removed or replaced for any reason. The pedestrian bridge was constructed as a long pipe, formed using a series of ellipsoid steel rings encircled by a grid of expanded sheets. The elliptical cross-section was selected as the most rational option considering the ratio between the required height and width of the cross-section for the walkway. The expanded sheets, used as the lining of the pedestrian bridge, have two roles: they function as the obligatory guard rail, while bearing part of the horizontal load and constituting an integral part of the bridge's structure. The walkway of the pedestrian bridge was constructed using wooden planks in which lights were fitted (Fig. 1(c)). The structure of the bridge is mounted on V-shaped reinforced concrete pillars with a variable cross-section (Fig. 1(c)), part of which includes reinforced concrete staircases at the ends [5].

The pedestrian bridge at the railway station in Osijek was constructed based on the winning design of a competition held in 2006 (Fig. 1(a)). The location of the pedestrian bridge is only a few meters from the location of the old steel crossing. It is situated at the most active point connecting the wider city center and the southern part of the city. In that context, the pedestrian bridge has a greater urban planning importance and the potential to transform the entire area. The pedestrian bridge is located in the historical area dominated by two buildings that are protected as cultural heritage sites: the historical building of the railway station on its eastern side, and the so-called Gutman building (narrow-gauge railway station) on its western side. The pedestrian bridge thus represents an interpolation into the cultural heritage area, contributing to it the design characteristic of its time (Fig. 3(b)). The pedestrian bridge is an elevated promenade located $6.50 \mathrm{~m}$ above the ground, with a view connecting two areas of a different morphology: the $19^{\text {th }}$ century upper town blocks on the north, and the early $20^{\text {th }}$ century industrial district to the south of the railway. The duality of urban morphology is reflected in the dimensions of the cross-section: in the southern part, toward Vrbaska street, the cross-section of the pedestrian bridge is lower (commensurate to the scale of family houses), while in the northern part, it is taller (commensurate to the scale of the multi-story blocks and Trg Lavoslava Ružičke) [31]. The architecture of the pedestrian bridge is coherent and moves from the horizontal to the vertical at regular intervals through the lining of clear glass and perforated sheets, evoking a certain dynamism. In addition to the aesthetic function, the perforated sheets also provide ventilation, which is important in the summer, when continuous natural ventilation is needed. Breaks in the floor plan, i.e., departure from the linearity, generate 
attractiveness and direct the gaze to views of the city visible through the glass lining (Fig. 1(a)). Although this architecture is attractive, it is far more than simple aesthetics: it functions as a crossing, creates a covered promenade as a new quality, connects separated parts of the city, and has become a new city landmark [31].

The second pedestrian bridge in Osijek, the one near the Sugar factory, consists of two identical sets of staircases and lifts that are integrated in pavilion form with a square floor plan, with emphasis placed on both ends of the pedestrian bridge (Fig. 16(a)). The basic planning concept is the linearity and symmetry of the entry pavilions around the central axis (Fig. 16(b)) [32]. The movement of pedestrians is linear, vectorial. This pedestrian bridge consists of reinforced concrete for most elements of the load-bearing structure and a combination of different materials and structural elements. That is, the structure of the side pavilions, i.e., the staircase and the lift shaft, is made from reinforced concrete, partly using deep beams; the central corridor above the railway tracks is a system of reinforced concrete beams and pillar. Meanwhile, above them, the semi-circular steel structure with a box profile is lined with transparent polycarbonate sheets. The sides are open to allow ventilation and to facilitate views of the urban environment. Despite the static form and the impression of massiveness owing to the use of reinforced concrete as the construction material, a dynamic sensibility is achieved by using different materials, contrasting colors (Fig. 16(b)), and a rhythmic shift in the full-empty relationship of the linings of the side pavilions (Fig. 16(a)).

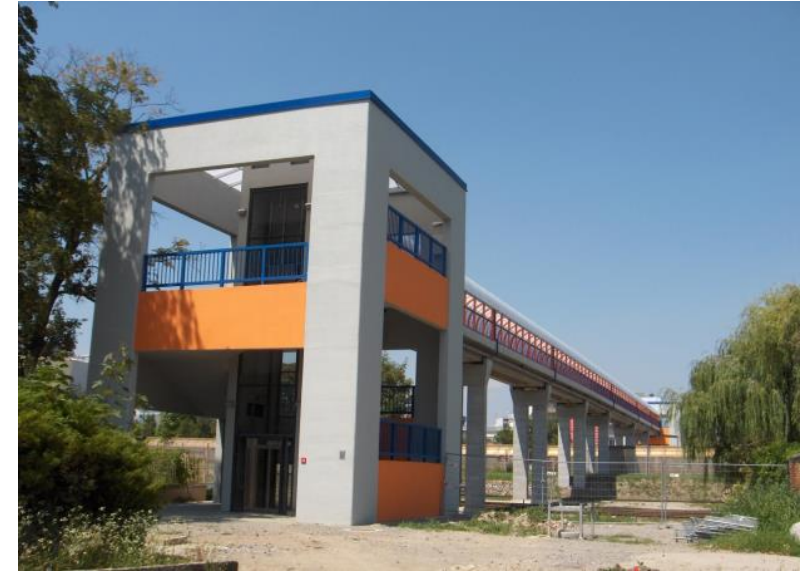

(a)

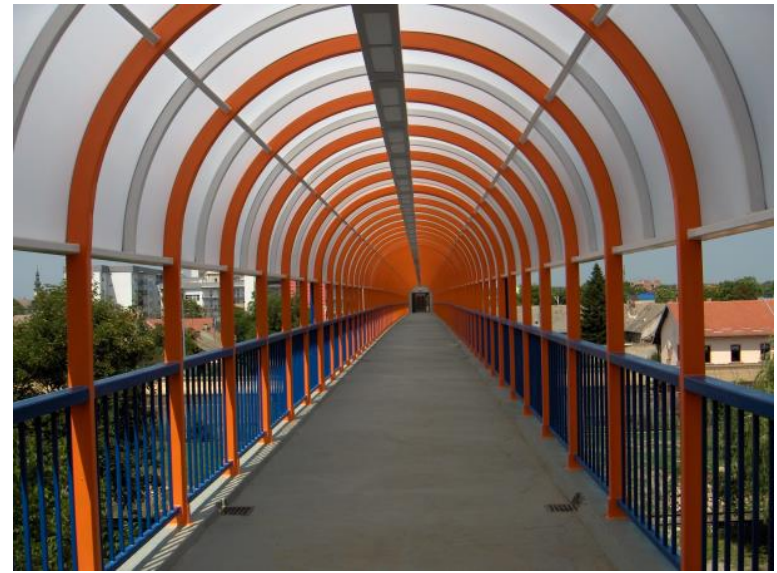

(b)

Figure 16 Pedestrian bridge over a railway corridor at the Sugar factory, Osijek, Croatia, architect: Assoc. Prof. Željko Koški, PhD, other authors: Prof. Zvonimir Marić, PhD, Prof. Damir Markulak, PhD, and Prof. Damir Varevac, PhD, 2005: (a) View from the southeast; (b) Interior of the pedestrian bridge

Pedestrian bridges in Osijek are equipped with lifts for persons with reduced mobility. The investor and owner of both pedestrian bridges is the local government of the City of Osijek. The structures of the new pedestrian bridges have had an effect on their surroundings, initiating a partial revitalization of the area around the railway corridor and improving the surrounding public surfaces, while the pedestrian bridges have become new elements in the city's image.

\section{CONCLUSION}

Following the analysis and comparison of a large number of pedestrian bridges and the overview of different original concepts, it may be concluded that a new area of architecture has emerged in the last few decades. This architecture involves a novel approach to designing structures. These structures in the past were standard constructions and primarily provided a safe crossing of heavy road and railroad traffic for pedestrians. The examples presented herein demonstrate the novel integration of construction and architecture, i.e., blurring the lines between specialist structural engineering and the artistic efforts of architects. Structural logic and architectural expression should be united in the design and construction process, and there should be interdisciplinary cooperation among all experts (constructors, architects, installers, traffic safety experts). The integrated approach to designing pedestrian bridges may elucidate 
the possibilities of span superstructures, the use of different materials, planning for day and night views, providing a comfortable climate, etc. The presented examples and their comparison showed the complexity of pedestrian bridges as uniquely designed structures, while illustrating various potential solutions and original architectural approaches. Pedestrian bridges have a significant effect on their immediate and wider spatial context; they improve it, introduce the potential for regeneration of the surrounding area (road or railway corridor), and have a significant impact on the city's image. Pedestrian bridges are less defined by the social component because serving as a crossing is their primary function. It may be concluded that the "form follows function" formula is mostly valid for designing pedestrian bridges. Architecture gives a new frame of uniqueness and an added aesthetic value to what was, until recently, a standard traffic structure (pedestrian crossing). It confers a special quality to the city as the creation of a new and modern urban identity, with a series of attractive views of the urban environment. The design and construction of pedestrian bridges has become a notable creative advancement in forming the identity and image of a city. It adds an artistic, attractive, and recognizable component to the basic traffic infrastructure, creating a symbol of the city, which is important in the current global and urbanized world.

\section{References}

[1] Baus, U.; Schlaich, M. 2008: Footbridges, Birkhäuser Verlag AG, Basel, Boston, Berlin.

[2] Salamak, M.; Fross, K. 2016: Bridges in Urban Planning and Architectural Culture, Procedia Engineering, 161, pp. 207-212. https://doi.org/10.1016/i.proeng.2016.08.530

[3] Jerković, S. 2007: Intervju Maurice Nio: Mislim da je nužno promijeniti sliku koja postoji o arhitekturi, Čovjek i prostor, 11-12, pp. 30-37.

[4] Archello: https://archello.com/fr/story/69807/attachments/photos-videos/2, Accessed 10 April 2021

[5] Mimica, V.; Frampton, K.; Glavan; D. 2000: Randić \& Turato: Arhitektura tranzicije, Mimica, V. (Ed.), Arhitekst, Zagreb, Croatia.

[6] Gangal, S. AECCAFE Blogs, 2011: https://www10.aeccafe.com/blogs/arch-showcase/2011/02/18/footbridge-inla-roche-sur-yon-france-by-bernard-tschumi-and-hugh-dutton/\#jp-carousel-4191, Accessed 10 April 2021

[7] Tang, M.-C. 2018: Forms and Aesthetics of Bridges, Engineering, 4, pp. 267-276. https://doi.org/10.1016/i.eng.2017.12.013

[8] Del Grosso, A. E.; Basso, P. 2010: Unconventional Structural Forms in Pedestrian Bridge Design, IABSE Symposium Report, 97, pp. 17-24. https://dx.doi.org/10.2749/222137810796025681

[9] Schlaich, M. 2005: Guidelines for the design of Footbridges, In Footbridge 2005 Second International Congress, Venice, Italy.

[10] Jurković, Ž. 2019: Evaluation Model of the Transformation Potential of Railway Corridors within Cities, Doctoral Thesis, University of Zagreb, Faculty of Architecture.

[11] Pogledaj.to: http://pogledaj.to/wp-content/uploads/archive/tschumi_bridge_france_\%20(2).jpg, Accessed 11 April 2020

[12] Welch, K., Pinterest: https://www.pinterest.com/kevin4451/pedestrian-bridge-inspiration/, Accessed 8 March 2020

[13] Riehle, D.: Software research and the industry. https://dirkriehle.com/2019/03/03/the-circular-footbridge-fromghost-in-the-shell, Accessed 22 December 2020

[14] ArchDaily: https://www.archdaily.com/111704/newport-station-grimshaw, Accessed 20 November 2020

[15] 3CINNO Group Co., Ltd.: Newport Station / Grimshaw. https://www.3cinno.com/led-curtain-screen-for-bridgevideo-wall/, Accessed 29 December 2020

[16] DETAlL Review of Architecture 3/2001, pp. 447.

[17] Archello: https://archello.com/story/94808/attachments/photos-videos/10, Accessed 29 December 2020

[18] Sophocleous, T.; Phocas, M. C.; Michael, A. 2013: Hybrid structures. A case of a pedestrian bridge, Structures and Architecture: Concepts, Applications and Challenges, In 2nd International Conference on Structures and Architecture, Cruz, P.J.S. (Ed.), CRC Press, Taylor \& Francis Group, pp. 323-324.

[19] Hollaway, L. C. 2013: Advanced fibre-reinforced polymer (FRP) composite materials in bridge engineering: materials, properties and applications in bridge enclosures, reinforced and prestressed concrete beams and columns, In Advanced Fibre-Reinforced Polymer (FRP) Composites for Structural Applications, Bai, J. (Ed.), Woodhead Publishing Series in Civil and Structural Engineering, pp. 582-630. http://dx.doi.org/10.1533/9780857098641.4.582 
Pedestrian Bridges as Elements of the New Spatial Identity of Cities

[20] Designboom: Adarc abstracts forms of houses to shape wooden footbridge in China. https://www.designboom.com/architecture/adarc-associates-foshan-city-heyue-road-pedestrian-bridge-china01-20-2016/, Accessed 22 May 2019

[21] Diary of a Desert Fox: https://diaryofadesertfox.files.wordpress.com/2013/01/img_2603.jpg, Accessed 9 May 2019

[22] Designboom: ADARC abstracts forms of houses to shape wooden footbridge in China. https://www.designboom.com/architecture/adarc-associates-foshan-city-heyue-road-pedestrian-bridge-china01-20-2016/, Accessed 22 May 2019

[23] MVSA Architects: Hilversum footbridge. https://mvsa-architects.com/project/projects-hilversum-footbridgetransportation-logistics/, Accessed 7 April 2019

[24] DETAIL Review of Architecture 5/2001, pp. 865.

[25] Rosemary's Blog: https://rosemarywashington.files.wordpress.com/2011/06/img_5403.jpg, Accessed 2 April 2019

[26] DesignThis 2013: Pedestrian Bridge in Esch sur Alzette, Luxembourg. https://www.designisthis.com/blog/en/post/pedestrian-bridge-esch-sur-alzette-luxembourg, Accessed 3 April 2019

[27] Dezeen: https://www.dezeen.com/2014/06/13/skyttlebron-railway-bridge-lund-sweden-metro-arkitekter-zigzags-onto-the-platforms/, Accessed 7 May 2019

[28] Hrvatska elektroprivreda 2007: Stoljeće svjetla u Zagrebu, 1907-2007, Zagreb, Croatia.

[29] Pogledaj.to: http://pogledaj.to/drugestvari/zeljeznica-spaja-liude-a-zeljeznicka-insfrastruktura-nekad-razdvaja/ Accessed 7 May 2019

[30] Premerl, T. (Ed.)1989: Arhitektonska ostvarenja u Hrvatskoj, Čovjek i prostor, 433, pp. 8-16.

[31] Jurković, Ž. 2010: Nathodnik u Osijeku, fenomen mjesta i doživljaj prelaženja, Čovjek i prostor, 668-671, pp. 4243.

[32] Koški, Ž.; Marić, Z.; Markulak, D.; Varevac, D. 2005: Idejni projekt Nathodnika kod Tvornice šećera Osijek.

Please cite this article as: Jurković, Ž.; Koški, Ž.; Lovoković, D.: Pedestrian Bridges as Elements of the New Spatial Identity of Cities, Electronic Journal of the Faculty of Civil Engineering Osijek-e-GFOS, 2021, 22, pp. 14-28, https://doi.org/10.13167/2021.22.2 